\title{
Ethics of children's participation in a Saudi biobank: an exploratory survey
}

\author{
Ghiath Alahmad, MD, PhD ${ }^{1,2}$ Tamer Hifnawy, MD, PhD ${ }^{3,4}$ and Kris Dierickx, $\mathrm{PhD}^{5}$
}

Purpose: The aim of this study was to investigate the ethical issues involved in children's participation in research biobanks in Saudi Arabia and the Middle East.

Methods: A survey of 160 respondents from four groups (researchers, physicians, medical students, and laypersons) was conducted at King Abdulaziz Medical City in Riyadh, Saudi Arabia.

Results: A clear and positive attitude toward pediatric clinical and genetic research inside and outside of Saudi Arabia was found. Parental consent is viewed as essential, with $60 \%$ saying parental consent is sufficient for children up to 12 , and $40 \%$ saying it is sufficient for children 12-18 years old. More than $90 \%$ of respondents preferred to gain approval from any child with a decision-making capability; 58.2 and $38.6 \%$ of them believed that children between 12 and 18 , and $>18$ years of age, respectively, can understand and thus give their approval for genetic research. Clear majorities in the study agreed with reconsenting children when they become adults, allowing them to withdraw at any time. A clear majority agreed that either parent could sign a consent form for their child to participate in a research biobank.

Conclusion: All four groups believed, to varying degrees, that elements of ethical consideration were critical when involving children in research.

Genet Med advance online publication 10 December 2015

Key Words: biobank; children's consent; ethics; genetic research; survey

research biobanks that include both adult and child data. The Saudi biobank context is very different from other biobanks, particularly those in Europe and North America, because of the region's distinct social issues and ethics system built on Islamic values. Saudi society is characterized by a large family size (eight members, on average), the presence of genetic isolates and semi-isolates, a high rate of consanguinity, and the youthfulness of its population: $32.5 \%$ of individuals are younger than 15 years and only $2 \%$ are older than the age of 65. ${ }^{18}$ Considering these social parameters, variations in ethical challenges may occur with regard to research biobanks. Article 25, the Saudi law of research ethics, issued in 2011 by the National Committee of Biomedical Ethics, states that it is permissible to conduct biomedical research on children. The article takes this position under the conditions that the research is in the best interest of the child, research risks are minimal, and informed written consent from a parent is collected. ${ }^{19}$ In addition, the governance of Saudi biobanks accepts children's participation in research studies and collects samples from children aged 10 and older. ${ }^{20}$

Very few surveys about research on stored samples have been conducted in the Middle East. Abou-Zeid et al. ${ }^{21}$ surveyed patients who were proxy participants of research in Egypt, obtaining the viewpoints of patients regarding stored sample research, including genetic samples. Alahmad et al. ${ }^{22}$ conducted

\footnotetext{
${ }^{1}$ King Abdullah International Medical Research Center (KAIMRC), Riyadh, Saudi Arabia; ${ }^{2}$ Center of Bioethics, Harvard Medical School, Boston, Massachusetts, USA; ${ }^{3}$ Department of Public Health and Community Medicine, College of Dentistry, Taibah University, Medina, Saudi Arabia; ${ }^{4}$ Faculty of Medicine, Beni Suef University, Beni Suef, Egypt; ${ }^{5}$ Centre for Biomedical Ethics and Law, Katholieke Universiteit Leuven, Leuven, Belgium. Correspondence: Ghiath Alahmad (ghiathalahmad@hotmail.com)
} 
a qualitative study about the ethics of research on stored samples in the Middle East, including samples taken from children.

Given the importance of research on children's stored samples, the distinctive context of the Saudi biobank, and the lack of publications in this specific area, we found it necessary to query the opinions of Saudi professionals and biobank participants with regard to this form of clinical and genetic pediatric research. Thus the aim of this research was to seek opinions on the importance of research on stored tissue samples from children, the validity of parental consent and child assent, which parent has the right to consent, a child's right to withdraw and to be re-consented, and who investigated their opinions regarding medical and genetic confidentiality inside and outside the child's family.

\section{MATERIALS AND METHODS}

\section{Study design}

This was a cross-sectional analytical study. A survey was conducted among a sample selected randomly from people working at or visiting King Abdulaziz Medical City, Riyadh City. The sample included 40 medical doctors at King Fahad Hospital, 40 researchers at King Abdullah International Medical Research Center, 40 medical students at King Saud bin Abdulaziz University for health Sciences, plus 40 visitors or patients' companions at King Fahad Hospital. To explore lay perspectives, visitors and patients' companions with medical backgrounds or those working on medical research teams were excluded. A total of 160 participants were included in our study.

A structured questionnaire was constructed based on interviews with professionals from the Middle East. ${ }^{22}$ The questionnaire was drafted in English and tested before data collection. The validity and feasibility of the questionnaire content was ensured through consultation with relevant experts: a medical doctor, a genetics researcher, and a researcher in medical quality management. Several additions and amendments were made to ensure that the questions were relevant, clear, and valid in the Saudi context. The questionnaire was translated into Arabic and the content was validated. The English copy was used for researchers, physicians, and students, whereas the Arabic copy was used only with laypeople.

All respondents completed the questionnaires by themselves, except for laypeople, among whom interview-based questionnaires were used. The questionnaires were collected during an 8-month period by two trained research coordinators with the assistance of one medical student who collected the surveys from medical students. The research study was briefly explained, participant's questions were answered, and their concerns, if they had any, were addressed. Then verbal consent was collected. No monetary compensation or other incentives were offered or given to the participants for participation in the study.

The questionnaire's reliability was calculated using the Cronbach $\alpha$ reliability coefficient to test for internal consistency; the 31-item questionnaire achieved a consistency coefficient of 0.863 , indicating a high degree of internal consistency. Test and retest reliability was ensured by a pretest study of five subjects before formal data collection commenced.
The interview schedule consisted of two parts: (1) the importance of research on children and (2) parental informed consent and child assent. Part I is a four-item attitude statement scale that evaluated the respondents' beliefs about the importance of research in general, and biobanking research in particular, using a five-point Likert scale including the categories of strongly disagree, disagree, not sure, agree, or strongly agree. The respondents were asked to rate the importance of conducting the research in Saudi Arabia as well as in other countries.

Part 2 of the research explored the attitude of subjects toward parental consent, child assent, re-consent, and withdrawal. Three items with a scale from 1 to 18 years were used to determine the beliefs regarding age sufficiency of parent's consent alone, child assent alone, or both. A special item was created to determine the gender of the parent who was entitled to sign the consent form for the child, namely, the father, mother, either of them alone, both, or neither of them. Three statements were used to determine the agreement on the need to re-consent the child when he/she becomes an adult, to modify consent information to be understood by children, and to respect a child's wish to withdraw; all measures were assessed on a five-point Likert scale.

\section{Ethical considerations}

Ethical approval was received from the institutional review board of the National Guard Health Affairs, Riyadh, Saudi Arabia. All respondents who agreed to participate were assured of confidentiality and had the right to withdraw at any time.

\section{Data curation and statistics}

The data were coded and analyzed using SPSS software version 19 for Windows 7 (IBM, Chicago, IL). A five-point Likert scale was transformed to a three-point Likert scale for the purpose of analysis. A five-point Likert scale was used to calculate the mean and SD for quantitative analysis. For inferential statistics, $\chi^{2}$, Student's $t$-test, and paired sample $t$-tests were used; $P<0.05$ was considered statistically significant.

\section{RESULTS}

\section{Personal characteristics}

The study sample comprised 160 respondents from four different groups consisting of nearly the same numbers of men and women (Table 1). The ages of the children and their educational levels were significantly different between groups. Students were the least likely to have children. All physicians had master's degrees or higher, whereas the majority of the other three groups had only diplomas or bachelor's degrees. A substantial minority of laypeople had secondary school or less as a final degree. It is worth noting that researchers had more training in research ethics compared with physicians and students.

\section{Experience of biomedical and genetic research conducted with adults and children}

Descriptive statistics of respondents revealed a high tendency to agree with the importance of clinical and genetic 
Table 1 Sociodemographic characteristics of the study sample

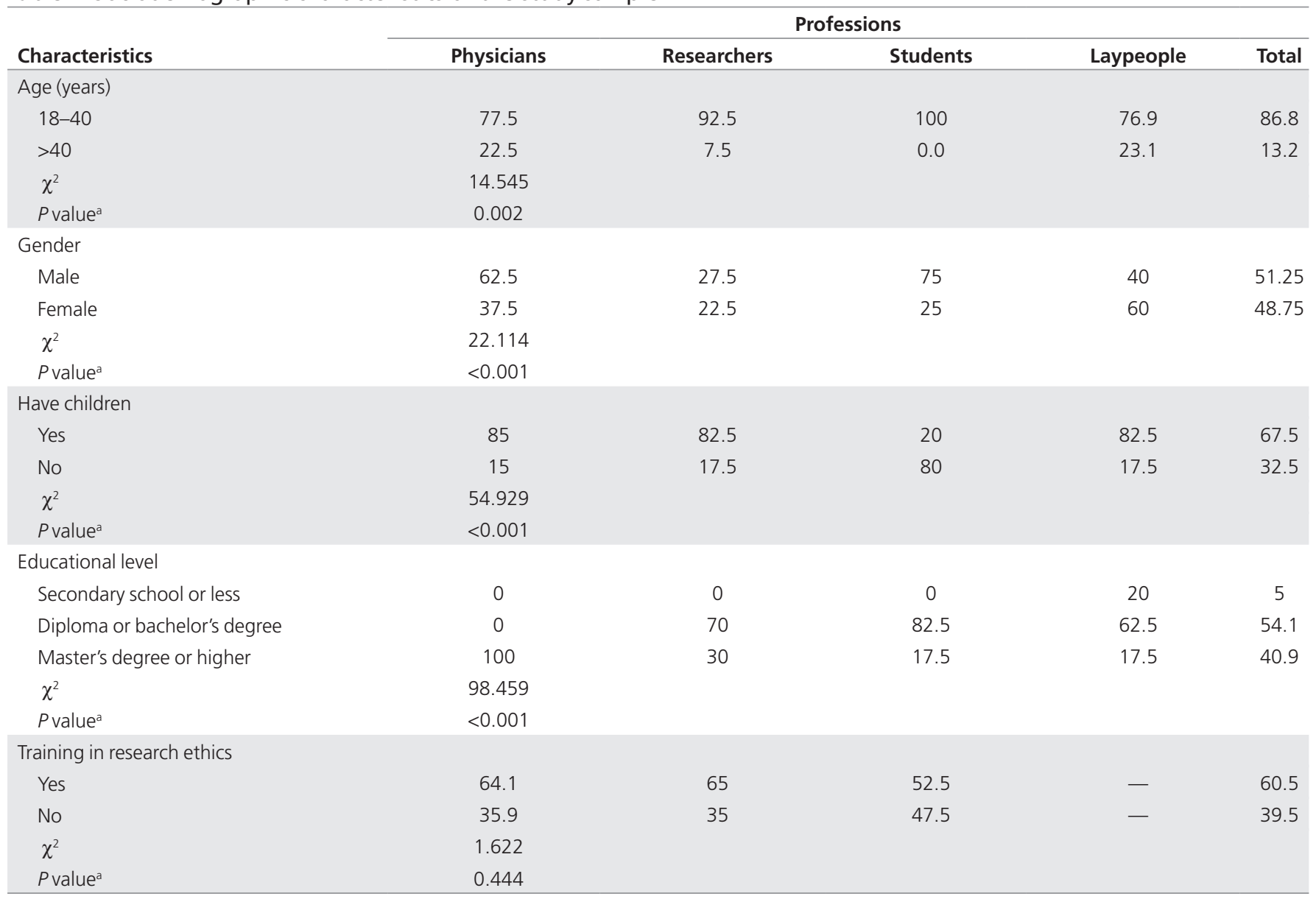

Data are percentages, unless otherwise indicated. Data are missing in some categories; percentages are calculated for those respondents from whom data were available. apearson $\chi^{2}$ test.

research conducted on children, both in general and in Saudi Arabia specifically (Table 2 ). The relation between profession and the importance of conducting clinical research was mildly significant $(P=0.049)$, with physicians followed by researchers, students, and laypeople agreeing that research was important.

No significant difference in the importance of clinical and genetic research inside or outside Saudi Arabia was found among respondents who have or do not have children.

\section{Attitudes toward consent for children to participate in research}

For research on children younger than 12 years, $60 \%$ of respondents believed that parents' consent alone was sufficient and that children should only participate in making a decision when $\geq 12$ years old (Table 3 ). Moreover, about $30 \%$ of respondents agreed that assent is required between ages 10-12 years (Figure 1). Around $40 \%$ of participants believed that there was no requirement to discuss participation with children until they were 18 years old. Except for some students, all participants agreed that for people older than 18 years, the consent of parents is not sufficient. We found that the number of people who agreed that children older than 12 years should assent was significantly different among laypeople (82.5\%) than among physicians (38.5\%) and students (47.5\%).

For genetic research, $3.2 \%$ of all respondents believed that children under the age of 12 could understand and give their assent for genetic research, whereas $58.2 \%$ believed that children can understand and give their assent when they are between 12 and 18 year old; however, 38.6\% still believed that participants had to be over 18 years of age to be able to understand the research and provide consent. Regarding those who believed that children under 18 years old could understand genetic research and give assent, the difference between laypeople (66.7\%) and physicians (55\%) was significant. For more than $50 \%$ of participants, minors between 16-18 years old can understand and assent for genetic research (Figure 1).

Almost $90 \%$ of all four groups agreed with the importance of the following statements: children's assent is important when they are able to do so $(91.9 \%)$; information must be adapted for minors $(82.9 \%)$; re-consent when the children become adults $(90.5 \%)$; respect the wishes of children if they want to withdraw (86.2\%). 
Table 2 Responses of participants toward the importance of research on children

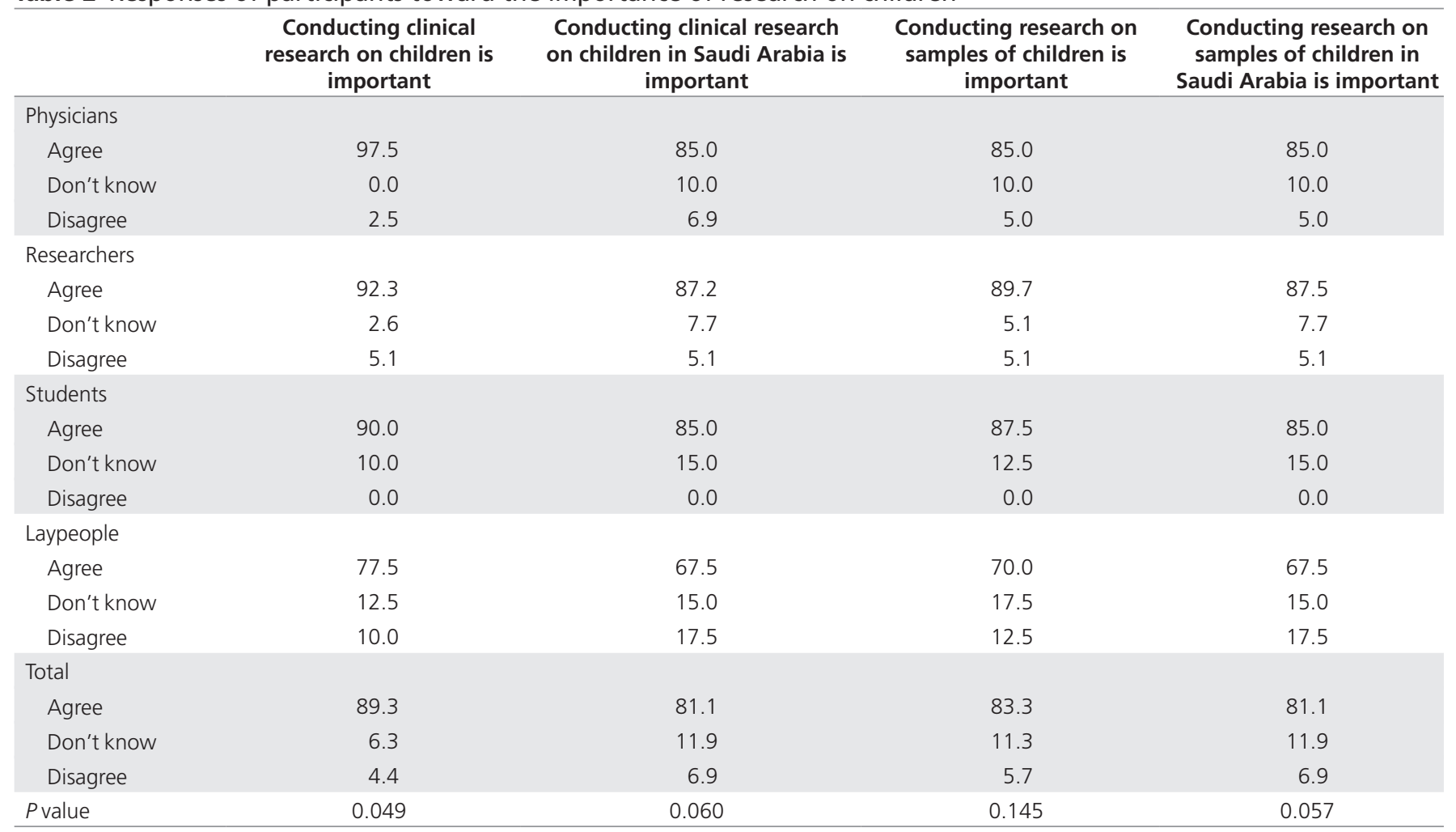

Data are percentages, unless otherwise indicated.

Table 3 Agreement on signing consent in association with different age groups for consent and child assent

\begin{tabular}{lccc}
\hline & \multicolumn{3}{c}{ Child's age (years) } \\
\cline { 2 - 4 } Consent question, by profession & $<\mathbf{1 2}$ & $\mathbf{1 2 - 1 8}$ & $>\mathbf{1 8}$ \\
\hline Until which age is parents' consent alone enough for child participation \\
in research without child assent? & 38.5 & 61.5 & 0.0 \\
$\quad$ Physicians & 72.5 & 27.5 & 0.0 \\
Researchers & 47.5 & 47.5 & 5.0 \\
Students & 82.5 & 17.5 & 0.0 \\
Laypeople & 60.4 & 38.4 & 1.3 \\
Total & 0.0 & 55.0 & 45.0 \\
At which age can a child understand genetic research and give assent? \\
Physicians & 2.6 & 61.5 & 35.9 \\
Researchers & 7.5 & 50.0 & 42.5 \\
Students & 2.6 & 66.7 & 30.8 \\
Laypeople & 3.2 & 58.2 & 38.6 \\
Total & \multicolumn{3}{l}{}
\end{tabular}

Data are percentages.

The number of respondents who agreed that any parent could sign the consent form (74.5\%) was significantly higher $(P<0.001)$ than the alternative options (both parents, father only, mother only, and neither of them). Fathers alone were preferred more often. No significant difference was found among the professional groups $(P=0.216)$ or between the two genders $(P=0.276)$ (Table 4$)$.

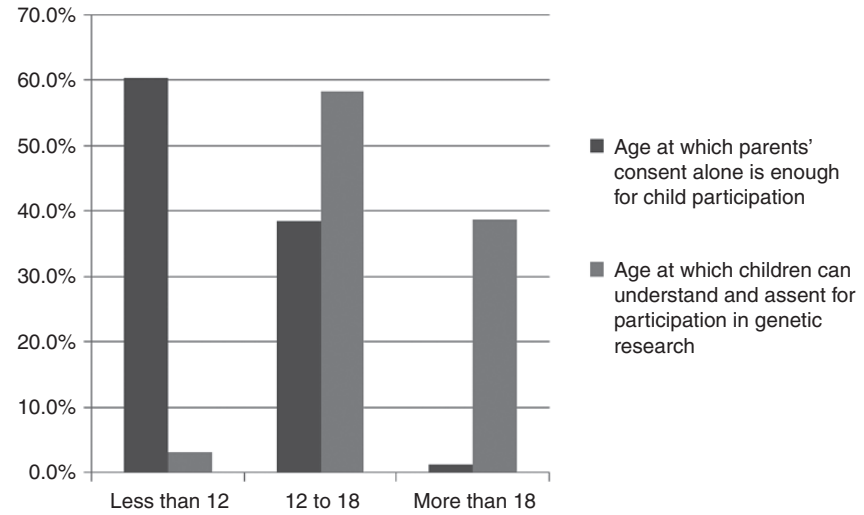

Figure 1 Age at which children can understand and assent to participation in genetic research and age at which parents' consent alone is enough for child participation.

\section{DISCUSSION}

This study comes from one country, but the data give a reasonable guide for research biobanks in the Gulf region and the Middle East. The majority of communities in these countries are Muslim and share similar social and economic values. They are characterized by a high percentage of children compared with the Western world. The Saudi biobank includes samples from children aged 10 years or older. Other biobanks in the region are expected to include children, especially those in Gulf countries that have relatively small populations. 
Knowing that Saudi Arabia is an Islamic country, respondents' views were discussed in light of Islamic opinions expressed by fatwas released by official juristic councils.

\section{Trends in attitudes toward pediatric research}

The results show a positive attitude toward pediatric clinical and genetic research, both inside and outside Saudi Arabia. This claim is supported by knowledge provided by physicians and researchers working directly or indirectly at King Abdullah International Medical Research Center, one of largest research centers in the region. Here, many educational activities related to medical research are organized for all kinds of professions, including courses about research methodologies, clinical trials, and biobanking research, plus other professional programs. Opinions in Saudi Arabia were not affected negatively by historical medical research violations. We did not detect any major medical scandals in Saudi Arabia as occurred in Europe, such as the Nazi trials in World War $\mathrm{II}^{23}$ or the Tuskegee experiments in America. ${ }^{24}$

Study results indicated that participants did not distinguish between the research conducted on biomedical samples and that conducted on persons. The participants seemed to consider that research on samples may be understood as genetic research, which includes exposing genetic information that is not only individual information but also familial ${ }^{25,26}$ and, in some cases like Saudi Arabia, even tribal.

However, some researchers contend that biomedical samples are not the same as a person, and therefore research done on human tissue samples is not the same as that done on the person himself..$^{10}$ This contention is contrary to the results of this study, as stated above.

Although there was no significant difference between professional groups, laypeople produced more lower results, which could be explained by their lower education levels and limited insight into research, as reported in other studies. ${ }^{27,28}$ Moreover, laypeople usually concentrate on the immediate benefits of research rather than the final results, as doctors do. ${ }^{2}$

Nevertheless, the attitudes of laypeople were positive, findings that are in line with a previous study that showed that $68.8 \%$ of subjects were willing to participate in clinical research, ${ }^{29}$ in

Table 4 Person(s) who can sign informed consent for child participation in clinical and genetic research

Who do you think should sign informed consent for child participation in clinical and genetic research?

\begin{tabular}{lccccc}
\cline { 2 - 6 } Profession & $\begin{array}{c}\text { Father } \\
\text { only }\end{array}$ & $\begin{array}{c}\text { Mother } \\
\text { only }\end{array}$ & $\begin{array}{c}\text { Both } \\
\text { parents }\end{array}$ & $\begin{array}{c}\text { None of } \\
\text { them }\end{array}$ & $\begin{array}{c}\text { Any } \\
\text { parent }\end{array}$ \\
\hline Physicians & 2.7 & 0.0 & 27.0 & 0.0 & 70.0 \\
Researchers & 10.3 & 0.0 & 25.6 & 0.0 & 64.1 \\
Students & 6.1 & 0.0 & 15.2 & 0.0 & 78.8 \\
Laypeople & 5.0 & 2.5 & 5.0 & 2.5 & 85.0 \\
Total & 6.0 & 0.7 & 18.1 & 0.7 & 74.5 \\
\hline
\end{tabular}

Data are percentages. agreement with other studies in Sweden and the United States. ${ }^{14}$ This attitude may be explained by the fact that many laypeople have degrees and understand the importance of research; moreover, many of those interviewed had previously engaged with the health-care system. They know that King Abdulaziz Medical City provides an advanced level of care and is a tertiary hospital where research ultimately leads to better care.

It can be argued that lay participants with children may have different opinions than childless participants, but the latter also agreed on the importance of research on children. However, it was unclear how many in our cohort, if any, had children involved in research, sample collection, or biobanks. One could question whether parental status influenced the responses to issues of research and biobanks. ${ }^{28}$ Would a person without children understand the developmental abilities of a child to make a reasonable decision about consent, denying consent, or the meaning of the research? Another issue is whether the parent views their child accurately or whether they still see their child as younger and less emotionally developed than they are. ${ }^{2}$

Participant responses showed that they did not think that clinical research is more important in Saudi Arabia than elsewhere. One possible explanation is that, although Saudi Arabia has a strong tribal structure and consanguineous marriage is common, people do not see this as sufficient reason for research to be needed at a greater level in Saudi Arabia than elsewhere in the world.

This positive attitude regarding research on children is in line with international guidelines such as those from the Declaration of Helsinki ${ }^{30}$ and the Council for International Organizations of Medical Sciences (CIOMS), ${ }^{31}$ although there are few regulations on research on children in the Middle East. ${ }^{32}$ Although our study was conducted in a Muslim country, the highly positive attitude of respondents contrasts with fatwa 67 (1992) of the International Islamic Fiqh Academy about prohibiting research on children. However, the respondents' attitudes are in line with more recent fatwas that permit research on children, like fatwa 161 (2006) by the International Islamic Fiqh Academy, ${ }^{33}$ fatwa 3/17 (2002) by the Islamic Fiqh Council ${ }^{34}$ and fatwa 598 (2008) by Dar-Alifta ${ }^{35}$; they also are in line with the opinion of the International Islamic Organization of Medical Sciences. ${ }^{36}$

\section{Consent for children's participation in biobanks}

Parental consent. Our respondents showed a highly positive attitude toward parental consent, with $60 \%$ saying parental consent was sufficient for children up to 12 years of age and $40 \%$ believing it is sufficient for children 12-18 years old. Laypeople provided the highest agreement.

A parent consenting to research on behalf of a minor child is a common situation. ${ }^{5,11,30}$ The consent should provide the information in a manner that allows the details of the research to be easily understood. The high percentage agreement by laypeople compared with other groups may be explained by thinking that children between 12 and 18 years old can readily understand the information. The necessity of parental consent is also 
explicitly mentioned in Islamic resources such as the Islamic Organization for Medical Sciences and fatwas such as no. 3/17 by the Islamic Fiqh Council, ${ }^{30}$ no. 161 by the International Islamic Fiqh Academy, ${ }^{33}$ and no. 598 by the Dar-Alifta. ${ }^{35}$

Even for children older than 18 years, $1.3 \%$ of respondents said that parents' consent alone is enough, whereas $38.6 \%$ still believe that a child is unable to understand and make decisions about participation without their parents' consent. This selection by respondents is related to common social factors in Saudi Arabia, where most people do not become independent just by becoming older than 18 years; they often remain living with their families and depend on parents. Of respondents, $38 \%$ said that parents' consent is enough when a child is between 12 and 18 years old. This finding is supported by other studies that show that children may face difficulties in understanding and making decisions. ${ }^{37}$ Islamic resources do not specify the age at which consent of parents alone is sufficient. ${ }^{38}$

Assent and age of understanding. In relation to child assent, more than $90 \%$ of respondents preferred to have assent from a child with decision-making capacity. Of the respondents, $58.2 \%$ believed that children between 12 and 18 years old could understand and give their assent for genetic research, whereas $38.6 \%$ still believed that children have to be $\geq 18$ years old. Laypeople were the most likely to agree that children younger than 18 years old could give assent.

Requiring assent by children supports the moral idea that children have to play a role in decisions related to their health and is consistent with other studies. ${ }^{2,6}$ Obtaining assent from children is a reflection of respect for their autonomy.

Children can develop the ability to make decisions about their health and give assent to participate in medical research at earlier ages. ${ }^{28}$ Often, a child who has a life-threatening illness can mature more quickly in his or her understanding of the significance of medical research. A child such as this may understand that if their tissue, blood, or other information is used long after their health struggle ends, the benefits for others is greater than their own. Indeed, some studies have recommended involving children in participation decisions at very young ages. ${ }^{39,40}$

The results fall in line with the normal development of children for understanding complex ideas. Many individuals default to the age of the majority when considering when a child has the right to consent. In some countries, the age of majority may be as young as 16 years, but commonly it is $\geq 18$ years. ${ }^{2,23}$ Each country has their own determining factors and, as such, the cultural and legal aspects can vary. Involving children in decision making is compatible with international documents such as those from CIOMS and the Declaration of Helsinki, which mentions the importance of considering a child's opinion. Also, CIOMS has stated that a 12- or 13-yearold child should be allowed to decide, which seems to be compatible with our results in that only $3.2 \%$ of our respondents believed that people under 12 can understand and give assent. This may explain why the Saudi biobank defines a minimum age of 10 years for allowing participation and assent.
Respondents' views matched Islamic opinion, as expressed by the Islamic Organization for Medical Sciences, about the importance of having a child's assent. No definitive age at which a child can give assent for medical research is specified by Islamic authorities ${ }^{38}$; rather, other factors, such as maturity and social development, play important roles in judging a child's decisionmaking abilities. Islamic views consider a child's capacity for judgment as a main factor in allowing him or her to make decisions, and each country defines the exact age of majority, which is different from country to country; it is 18 years in Saudi Arabia.

Re-consent. With regard to re-consenting children when they become adults, for genetic research they are part of a clear majority whose previous participation was bestowed by their parents' consent. Therefore, upon reaching adulthood, participants have the right to override the decisions their parents made for them when they were children. ${ }^{40}$ Children must have the ability to state when and if they are willing to continue in the research, have the ability to withdraw, have the ability to consent if they are at an age and level to understand the consent, and must be able, as adults, to take over the consent. However, re-consent may face some technical difficulties related to the success of contacting participants and their response rate. Some biobanks consider participants to have agreed to continue participating in the biobank when they become adults unless they come forward and declare their withdrawal, which is also the practice of the Saudi biobank. ${ }^{20}$ There are no Islamic resources that address the issue of re-consenting for clinical research purposes when children become adults.

Withdrawal. When questioning the right to withdraw consent, the majority of our respondents agreed with allowing a child to withdraw at any time without consequence-even before they turn 18 years old. A child should always have the opportunity to withdraw from a study no matter who signed the consent form. ${ }^{41}$ If the child is uncomfortable with the study's intent, the child should have the right to withdraw. The right to withdraw is not contingent on the person who consents to the study but to the person actively involved in the study-in this case, the child. Some even say that the withdrawal right is much more important for children than for adults, considering that children participated in the biobank only because of parental consent. ${ }^{2}$

Which parent? A clear majority of respondents agreed that either parent can sign the consent for a child to participate in a research biobank, followed by both parents together, fathers alone, and, last, mothers alone. No significant difference was found among the professional groups.

In a previous study with genetic researchers from the Middle East, consent of both parents was preferred for a child's participation in a research biobank, but fathers were given priority over mothers in cases of disagreement. ${ }^{22}$ There are no similar studies of this issue, except what was written by Burke and Diekema $^{40}$ about preferring not to perform any procedure in the case of disagreement between the parents. 


\section{ORIGINAL RESEARCH ARTICLE}

For individuals in many countries, the question of which parent should sign the consent form can cause confusion as to why the decision matters-any parent should have equal rights to sign a consent form. In reality, however, there are different cultural and legal considerations involved in this issue. In some societies, such as Saudi society, where fathers have traditionally held the decision-making power in the family structure, the question is more justified; it is expected that fathers will be given priority. It is noteworthy, however, that both parents' consent was preferred by the majority of respondents.

In Islam there is a certain orderliness of child guardians who have the right to make decisions on a child's behalf; they are usually the males in the family: father, then grandfather, then brother. ${ }^{42}$ However, it is interesting to note that the majority of respondents said they prefer that decisions be made by both parents rather than fathers only. In addition, from an Islamic point of view, the male preference can be challenged, because limiting guardianship to males has not been stated in Islamic resources except in reference to guardianship in marriage and the inheritance of orphans. ${ }^{38}$ Joint consent by both parents may be a good solution.

\section{Results and their potential implications}

Implementing Regulations of Ethics of Research on Living Creatures contains most of the ethical guidelines for conducting research in Saudi Arabia, and it is still undergoing modifications and updates resulting from recent developments and debates. The results of this study may have an effect on future updates to Saudi law regarding research ethics. This is especially true of the section regarding regulating research biobanks, which was touched on only briefly in this study and is an area that will benefit from future research and additions or modifications.

This study may also support researchers and lawmakers who are proponents of using children as research subjects and who believe such research should be ethically regulated and take into account social and cultural mores in Saudi Arabia. We hope that other research builds on this study with the aim of creating better regulations concerning medical research on living child subjects, not only in Saudi Arabia but also in the surrounding countries.

\section{Conclusions}

The conclusion of this study is overwhelmingly in favor of parents providing consent for children in research studies until a child is of an age to provide his or her own consent. The study demonstrated that physicians had a more positive response to the use of children in research studies. Respondents believed it was important to encourage children to take an active role in their involvement by deciding to continue if parents consented, to withdraw if that is what they felt was right, and to ensure that children could re-consent upon reaching adulthood. All the components of adult consent to participate in research were critical for children in research but with the added elements of allowing children to withdraw and/or re-consent, and adapting all consent materials to a level a child could understand. The study showed, to varying degrees, that all four groups believe that these elements of ethical consideration are critical. However, the group with the least understanding of ethics involving research had a smaller portion of respondents given the importance of children's involvement in research. This demonstrates the importance of education about research, specifically children in research, for society as a whole.

\section{Limitations}

There are many limitations of this study. First, this research presents a view of professional people whose ideas may have been influenced positively because they work in the research center and hospital where the study was conducted. Second, even if efforts are made to clarify the concepts of clinical and genetic research for laypeople, their understanding may not reach the same level of that of individuals who have more medical knowledge and experience. Third, this article discusses potential participants' opinions in theory, which may not accurately reflect the actual practical situation when they participate in a biobank, where their responses may be affected by concerns or fears, especially those related to confidentiality. Fourth, because this study was conducted in a certain geographic area, the results may not be generalizable to neighboring places that may show some similarities but also some differences.

\section{ACKNOWLEDGMENTS}

The authors thank the two research coordinators, Aayah Gohore and Lubna Saleh, and medical student Sultan Al-Howti, who collected the questionnaires and the answers from respondents.

\section{DISCLOSURE}

The authors declare no conflict of interest.

\section{REFERENCES}

1. Gurwitz D, Fortier I, Lunshof JE, Knoppers BM. Research ethics. Children and population biobanks. Science 2009;325:818-819.

2. Hens K, Nys H, Cassiman JJ, Dierickx K. Genetic research on stored tissue samples from minors: a systematic review of the ethical literature. Am J Med Genet A 2009;149A:2346-2358.

3. Samuël J, Knoppers BM, Avard D. Paediatric biobanks: what makes them so unique? J Paediatr Child Health 2012;48:E1-E3.

4. Klima J, Fitzgerald-Butt SM, Kelleher KJ, et al. Understanding of informed consent by parents of children enrolled in a genetic biobank. Genet Med 2014;16:141-148.

5. Hens K, Cassiman JJ, Nys H, Dierickx K. Children, biobanks and the scope of parental consent. Eur J Hum Genet 2011;19:735-739.

6. Holm S. Informed consent and the bio-banking of material from children. Life Sci Soc Policy 2005;1:16.

7. Kaufman D, Geller G, Leroy L, Murphy J, Scott J, Hudson K. Ethical implications of including children in a large biobank for genetic-epidemiologic research: a qualitative study of public opinion. Am J Med Genet C Semin Med Genet 2008;148C:31-39.

8. Hens K, Van El CE, Borry P, et al.; PPPC of the European Society of Human Genetics. Developing a policy for paediatric biobanks: principles for good practice. Eur J Hum Genet 2013;21:2-7.

9. Ries NM, LeGrandeur J, Caulfield T. Handling ethical, legal and social issues in birth cohort studies involving genetic research: responses from studies in six countries. BMC Med Ethics 2010;11:4. 
10. Hens K, Snoeck J, Nys H, Cassiman JJ, Dierickx K. An exploratory survey of professionals on the use of stored tissue samples from minors for genetic research. Genet Mol Res 2010;9:973-980.

11. Ruiz-Canela M, Valle-Mansilla JI, Sulmasy DP. Researchers' preferences and attitudes on ethical aspects of genomics research: a comparative study between the USA and Spain. J Med Ethics 2009;35:251-257.

12. Pulley JM, Brace MM, Bernard GR, Masys DR. Attitudes and perceptions of patients towards methods of establishing a DNA biobank. Cell Tissue Bank 2008;9:55-65.

13. Hoeyer K, Olofsson BO, Mjörndal T, Lynöe N. Informed consent and biobanks: a population-based study of attitudes towards tissue donation for genetic research. Scand J Public Health 2004;32:224-229.

14. Kettis-Lindblad A, Ring L, Viberth E, Hansson MG. Genetic research and donation of tissue samples to biobanks. What do potential sample donors in the Swedish general public think? Eur J Public Health 2006;16:433-440.

15. Joseph JW, Neidich AB, Ober C, Ross LF. Empirical data about women's attitudes toward a biobank focused on pregnancy outcomes. Am J Med Genet A 2008;146A:305-311.

16. Goldenberg AJ, Hull SC, Botkin JR, Wilfond BS. Pediatric biobanks: approaching informed consent for continuing research after children grow up. J Pediatr 2009;155:578-583.

17. Jackson C, Dixon-Woods M, Tobin M, Young B, Heney D, Pritchard-Jones K. Seeking consent to tissue banking: a survey of health professionals in childhood cancer. Eur J Cancer Care (Engl) 2009;18:391-400.

18. Saudi Export Developing Center DoSal. Demographic Survey in 1428 AH (2007 AD). Ministry of Economy and Planning: Riyadh, Saudi Arabia, 2007.

19. King Abdulaziz City of Science and Technology (KACST). Implementing Regulations of Ethics of Research on the Living Creatures. King Abdulaziz City of Science and Technology: Riyadh, Saudi Arabia, 2013.

20. KAIMRC. The Governance of Saudi Biobank. Centre KAIMR: Riyadh, Saudi Arabia, 2011

21. Abou-Zeid A, Silverman H, Shehata M, et al. Collection, storage and use of blood samples for future research: views of Egyptian patients expressed in a cross-sectional survey. J Med Ethics 2010;36:539-547.

22. Alahmad G, Al Jumah M, Dierickx K. Confidentiality, informed consent, and children's participation in research involving stored tissue samples: interviews with medical professionals from the Middle East. Narrat Inq Bioeth 2015;5: 53-66.

23. Grabitz H. Problems of Nazi trials in the Federal Republic of Germany. Holocaust Genocide Stud 1988:3:209-222.

24. Reverby S. Tuskegee's Truths: Rethinking the Tuskegee Syphilis Study. University of North Carolina Press: Chapel Hill, NC, 2000.

25. Ashcroft R. The ethics of reusing archived tissue for research. Neuropathol Appl Neurobio/ 2000;26:408-411.
26. Deschênes M, Cardinal G, Knoppers BM, Glass KC. Human genetic research, DNA banking and consent: a question of 'form'? Clin Genet 2001;59: 221-239.

27. Ahmad K. Drug company sued over research trial in Nigeria. Lancet 2001;358:815.

28. Cousins $G, M c G e e ~ H$, Ring $L$, et al. Public perceptions of biomedical research: $a$ survey of the general population in Ireland. Psychol Rep 2005:8.

29. Al-Jumah M, Abolfotouh MA, Alabdulkareem IB, et al. Public attitude towards biomedical research at outpatient clinics of King Abdulaziz Medical City, Riyadh, Saudi Arabia. East Mediterr Health J 2011:17:536-545.

30. World Medical Association. World Medical Association Declaration of Helsinki: ethical principles for medical research involving human subjects. JAMA 2013;310:2191-2194.

31. Council for International Organizations of Medical Sciences; World Health Organization. International Ethical Guidelines for Biomedical Research Involving Human Subjects. CIOMS, WHO: Geneva Switzerland, 2002.

32. Alahmad G, Al-Jumah M, Dierickx K. Review of national research ethics regulations and guidelines in Middle Eastern Arab countries. BMC Med Ethics 2012;13:34.

33. International Islamic Figh Academy (IIFA). Decision about Islamic controls of biomedical research on humans. 161 (17/10). Amman 2006.

34. Islamic Figh Council (IFC). Stem cells. Makkah. 2002. http://www.themwl.org/ Fatwa/default.aspx d $=1$ \& cidi $=152 \& \mid=A R \& c i d=12$.

35. Dar al-Afta al-Misriyyah. Fatwa using stem cells in scientific experiments. 698. Cairo 2008

36. Islamic Organization for Medical Sciences (IOMS). International ethical guidelines for biomedical research involving human subjects-Islamic view. In: Islamic Organization for Medical Sciences (ed). Islamic Universal Charter of Medical Health Ethics. Islamic Organization for Medical Sciences (IOMS): Kuwait, 2005:129-301.

37. Boddington P, Gregory M. Adolescent carrier testing in practice: the impact of legal rulings and problems with "gillick competence". J Genet Couns 2008; 17:509-521.

38. Alahmad G, Dierickx K. Pediatric research ethics: Islamic perspectives. Br J Med Med Res 2015;5:1158-1168.

39. Hens K, Nys H, Cassiman JJ, Dierickx K. The storage and use of biological tissue samples from minors for research: a focus group study. Public Health Genomics 2011;14:68-76.

40. Burke W, Diekema DS. Ethical issues arising from the participation of children in genetic research. J Pediatr 2006;149(suppl 1):S34-S38

41. Alderson P. Young Children's Rights: Exploring Beliefs, Principles and Practice. Jessica Kingsley: London, 2008.

42. Shankeeti M. Ahkam Al-Jeraha Al-tebia [The Rules of Medical Surgery]. Maktabet Al-Sahaba: Jeddah, Saudi Arabia, 1994. 